\title{
EHP in low voltage networks: Understanding the effects of heat emitters and room temperatures
}

Link to publication record in Manchester Research Explorer

\section{Citation for published version (APA):}

Navarro-Espinosa, A., Good, N., Zhang, L., Mancarella, P., \& Ochoa, L. N. (2015). EHP in low voltage networks: Understanding the effects of heat emitters and room temperatures. In IEEE/PES PowerTech 2015 (pp. 1-5)

\section{Published in:}

IEEE/PES PowerTech 2015

\section{Citing this paper}

Please note that where the full-text provided on Manchester Research Explorer is the Author Accepted Manuscript or Proof version this may differ from the final Published version. If citing, it is advised that you check and use the publisher's definitive version.

\section{General rights}

Copyright and moral rights for the publications made accessible in the Research Explorer are retained by the authors and/or other copyright owners and it is a condition of accessing publications that users recognise and abide by the legal requirements associated with these rights.

\section{Takedown policy}

If you believe that this document breaches copyright please refer to the University of Manchester's Takedown Procedures [http://man.ac.uk/04Y6Bo] or contact uml.scholarlycommunications@manchester.ac.uk providing relevant details, so we can investigate your claim.

\section{OPEN ACCESS}




\title{
EHP in Low Voltage Networks: Understanding the Effects of Heat Emitters and Room Temperatures
}

\author{
Alejandro Navarro-Espinosa, Nicholas Good, Lingxi Zhang, \\ Pierluigi Mancarella and Luis F. Ochoa \\ School of Electric and Electronic Engineering \\ The University of Manchester \\ Manchester, UK
}

\begin{abstract}
The adoption of Electric Heat Pumps (EHPs) at residential level can support the decarbonization of domestic heating. However, these new loads can produce technical problems in low voltage ( $\mathrm{LV})$ distribution networks. This work studies the EHP technical impacts in LV feeders, analyzing potential actions to minimize them. Particularly, two cases are investigated: the utilization of different heat emitters and the selection of different indoor temperatures. These cases are explored by using a Monte Carlo approach to cater for the uncertainty of $L V$ demand. Daily one-minute resolution profiles are adopted for the domestic energy consumption in each of the sensitivities considered. The methodology is applied on three real UK LV networks. Results show that the decrease in the set temperature leads to a small reduction in the likelihood of technical impacts, whereas the utilization of underfloor heating can significantly reduce the likelihood of such impacts, resulting in a higher EHP penetration.
\end{abstract}

Index Terms-electric heat pumps, low carbon technologies, low voltage distribution networks.

\section{INTRODUCTION}

Today, there is a general consensus about the necessity of reducing anthropogenic carbon emissions [1]. In the UK, one possible option to contribute to this objective is the decarbonization of domestic heating, which accounts for $85 \%$ of the energy consumption in the residential sector [2]. The adoption of electric heat pumps (EHPs) could help to achieve such decarbonization through replacement of gas boilers for heat provision. However, this will increase the electricity requirement (energy and power) at household level. Furthermore, considering that customers are connected to low voltage (LV) distribution networks, it is likely that this infrastructure will experience technical problems (e.g., voltage drop below the limits, congestion, etc.) [3].

To understand the extent of the potential problems, this work explores in detail the impacts of EHP in LV distribution networks through the utilization of a Probabilistic Impact Assessment Methodology [4], realistic high resolution load and EHP modelling [5], as well as real UK LV feeders. Few works have been able to study such impacts at the requisite temporal and spatial resolution because of the lack of detailed high-resolution models of thermal technologies and/or the lack of real LV networks models. For instance, in [6], only daily hourly diversified profiles (electricity and heating demand) and synthetic networks are used. In [3] and [7], the EHP impacts are studied using generic networks. There, the EHP modelling was based on real $\mu \mathrm{CHP}$ data and real EHP data, respectively. This allowed assessing the impacts of EHPs considering the specific scenario when the data was collected. However, it cannot be directly used for understanding other conditions. In contrast, the model presented in [5] allows the creation of synthetic one-minute resolution EHP profiles, considering the interaction between the EHP, the heat emitter and the household. It is precisely because of this flexibility that the model presented in [5] is used in this work for the creation of load and EHP profiles. In fact, this model enables the analysis of all possible combinations among the main parameters that determine the domestic energy consumption (electricity and heating requirement) at residential level, such as insulation level of houses, outdoor and indoor temperatures, heat unit types, heat delivery system, etc.

In this context, the model from [5] is used to analyze the effects of the indoor temperature selection (room set temperature with and without setback) and the heat emitter type (radiator and underfloor heating). To do this, hundreds of profiles for different set temperatures and heat emitters are created. Additionally, to cater for the inherent uncertainties in LV networks, such as the location, size and behavior of loads and EHPs, the Probabilistic Impact Assessment Methodology proposed in [4] and also used in [3] is implemented. Thus, a time-series simulation framework and a three-phase four-wire representation of real UK LV networks are implemented and solved in OpenDSS [8].

The rest of the paper is structured as follows. Section II describes the proposed methodology. The Case Study is presented in section III. Section IV presents a sensitivity case by incorporating a setback temperature (lower limit) in all the studied cases. The main conclusions are drawn in section V.

\section{Methodology}

\section{A. Profiles Creation}

One-minute resolution profiles for loads and EHPs are developed. These profiles are created by using the domestic 
energy consumption model presented in [5]. This model considers the electrical appliances, the domestic hot water (DHW) consumption, the heating unit characteristics, the heat distribution system and the requirement for space heating.

The electrical appliance model is based on the tool presented in [9], which provides the occupancy pattern per household and the corresponding electricity consumption of each appliance. These outputs are used for the DHW model, which combines the occupancy and the operation of hot water related appliance with DHW consumption rates (liters/min) in order to create a residential DHW profile. The EHP operation is modelled taking into account its heat production and electricity consumption according to the source temperature (air in the case of the air source heat pump, ASHP, used in this work) and the return temperature from the heat distribution system (i.e., hot water pipes connecting the EHP, DHW tank and the heat emitter). Finally, the requirements for space heating are determined by the characteristics of the heat emitter (e.g., radiator or underfloor heating), the ambient temperature, the set temperature and the building characteristics.

It is worth mentioning that the outdoor and indoor temperature, the house insulation level, the heat gain (i.e., cooking, human metabolism and solar radiation) and the heat losses are included in this model. Thus, the model enables the creation of detailed domestic energy consumption profiles, producing fully related load and EHP profiles per household. This means that the potential coincidence between the heat and power consumption in each house is incorporated and therefore the additional power requirement due to the electrification of heat (EHP operation) is adequately modelled, which is particularly important for network studies.

The flexibility of this model enables the analysis of relevant variables in the hosting capacity of EHP in LV feeders. Particularly, this work studies the impacts of different heat emitters (radiator and underfloor heating) and different room temperatures (set temperature) on the performance of LV feeders.

\section{B. Probabilistic Impact Assessment}

To consider the uncertainties related with loads and EHPs (i.e., location, size and behavior), a Monte Carlo approach (as in [3] and [4]) is used in this work. To understand the impacts of the progressive residential EHP adoption, different penetration levels are studied. Here, penetration level is defined as the percentage of houses with EHP. Eleven penetration levels, ranging from 0 to $100 \%$ (in steps of 10\%), are investigated per feeder.

The methodology consists of the random allocation of load profiles in a particular feeder. Then, according to a given penetration level, the houses are randomly selected to have an EHP. Next, the corresponding EHP profile is allocated to each selected house. This profile is created for the particular characteristics of the selected house and is consistent with the corresponding occupancy pattern. Once the load and EHP profiles are allocated, a time-series power flow is executed via OpenDSS [8]. The load imbalance in the feeders is fully considered through the three-phase four-wire representation. With the power flow results, one voltage and one congestion
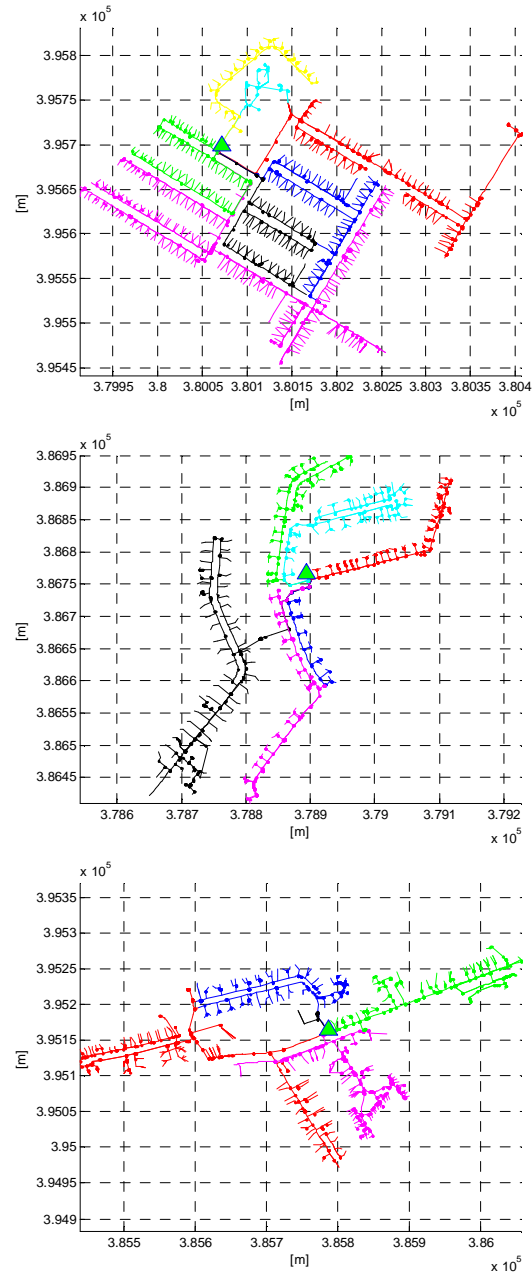

Figure 1. LV Networks

metric are calculated. This process is repeated one hundred times per penetration level for each feeder.

The two metrics implemented to analyze the EHP impacts are the percentage of customers with voltage problems and the utilization level at the head of the feeder. The former checks each customer's voltage according to standard BS EN 50160 [10] and then presents the average and +/- one standard deviation of non-compliant customers from the 100 simulations per penetration level. The latter calculates the ratio between the hourly maximum current and the ampacity at the head of the feeder, also presenting the average value $+/$ - one standard from the Monte Carlo approach.

\section{Network Data}

To analyze the effect of different heat emitters and room temperatures, the Probabilistic Impact Assessment is applied in three real UK LV distribution networks from the North West of England (Fig. 1). These network were modeled based on GIS data (topology, conductor characteristics, load locations and phase connections), adopting a three-phase fourwire representation to capture the inherent imbalance nature of LV systems. The feeder length (including service cables) and the number of loads per feeder of each network can be seen in Table I. 
TABLE I. FEEDER FEATURES

\begin{tabular}{c|c|c|c}
\cline { 2 - 4 } & Feeder & Length (m) & No. of Customers \\
\hline Network 1 & 1 & 1,716 & 71 \\
\cline { 2 - 4 } & 2 & 1,423 & 58 \\
\cline { 2 - 4 } & 3 & 1,107 & 50 \\
\cline { 2 - 4 } & 4 & 4,197 & 186 \\
\cline { 2 - 4 } & 5 & 1,065 & 61 \\
\cline { 2 - 4 } & 6 & 410 & 23 \\
\hline \multirow{4}{*}{ Network 2 } & 7 & 559 & 22 \\
\cline { 2 - 4 } & 1 & 1,070 & 31 \\
\cline { 2 - 4 } & 2 & 418 & 13 \\
\cline { 2 - 4 } & 3 & 2,471 & 48 \\
\cline { 2 - 4 } & 4 & 1,138 & 26 \\
\hline \multirow{5}{*}{ Network 3 } & 5 & 919 & 29 \\
\cline { 2 - 4 } & 2 & 1360 & 37 \\
\cline { 2 - 4 } & 3 & 2,903 & 111 \\
\cline { 2 - 4 } & 4 & 1,223 & 86 \\
\hline
\end{tabular}

\section{CASE STUDY}

For the base case, hundreds of loads and the corresponding EHP profiles are created assuming modern UK semi-detached houses (built between 1945 and 1982) for a cold day. The outdoor temperature varies between $0^{\circ} \mathrm{C}$ and $4.7^{\circ} \mathrm{C}$ during the day (daily average of $1.7^{\circ} \mathrm{C}$ ). The heat emitter and the set temperature (required indoor temperature) are considered to be a radiator and $21^{\circ} \mathrm{C}$, respectively, for all the properties.

The Probabilistic Impact Assessment is executed for each of the feeders for the three LV networks implemented and then the percentage of customers with voltage problems and the utilization level at the head of the feeder are determined for each of the one hundred simulations, allowing the calculation of the average and standard deviation of these values. As an example, the voltage and congestion metrics are shown in Fig. 2 and Fig. 3, respectively, for Network 1. Thus, in Fig. 2, it is possible to observe that only feeders 1 and 4 present voltage problems, having the first occurrence of issues at $40 \%$ of penetration level. These results also show that the average number of customers with voltage problems is larger than $10 \%$ if the penetration level is above $60 \%$ for this particular network. On the other hand, from the congestion point of view, Fig. 3 indicates that feeders 1 to 4 reach the maximum capacity $(100 \%)$ at some penetration level. In fact, the average utilization level in feeder 4 is close to $100 \%$ as early as $20 \%$ of penetration level.

In order to summarize the results for the three LV networks under analysis, Table II shows the penetration level when the problems first occur for voltage and congestion. The feeders without any problem (i.e., they can host $100 \%$ of EHP penetration) are not shown in this table. Hence, 7 out of the 17 feeders studied (41\% of them) present problems for hosting EHPs. Table II indicates that most of the problems are related to congestion issues.

\section{A. Modification of Room Temperature and Heat Emitter}

The adoption of EHPs at residential level leads to technical problems (mainly congestion) in some of the feeders under analysis. This is a bottle neck for the potential reduction of carbon emission for these feeders. One possible alternative to minimize those problems is the reduction of the set temperature; this means the availability of each household to decrease its required indoor temperature.

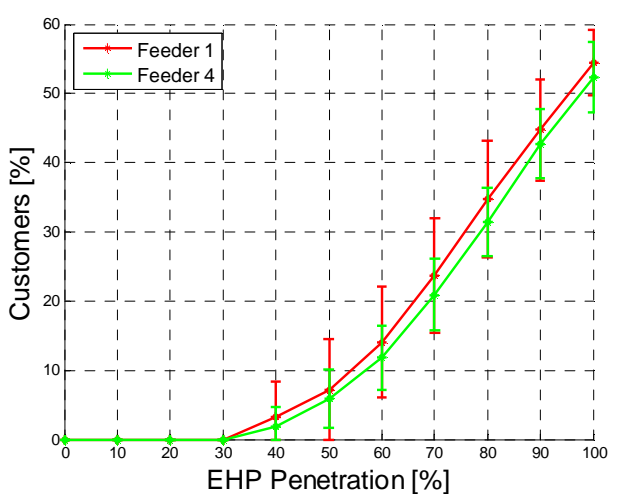

Figure 2. Percentage of customers with voltage problems - Network 1

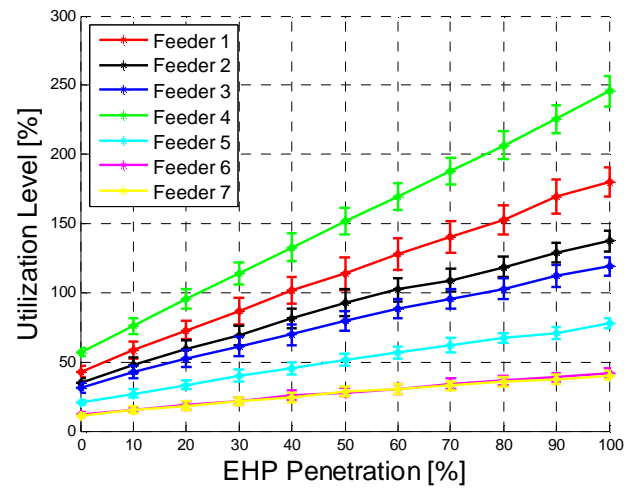

Figure 3. Utilization level at the head of the feeder - Network 1

TABLE II. PENETRATION LEVEl (\%) With Problems

\begin{tabular}{c|c|c|c|c}
\cline { 2 - 5 } & Feeder & Voltage & Congestion & Bottleneck \\
\hline \multirow{3}{*}{ Network 1 } & 1 & 40 & 40 & 40 \\
\cline { 2 - 5 } & 2 & None & 60 & 60 \\
\cline { 2 - 5 } & 3 & None & 80 & 80 \\
\cline { 2 - 5 } Network 2 & 4 & 40 & 30 & 30 \\
\hline \multirow{2}{*}{ Network 3 } & 3 & None & 70 & 70 \\
\cline { 2 - 5 } & 3 & None & 30 & 30 \\
\hline
\end{tabular}

This straightforward action will lead to lower energy consumption and potentially to an increase in the EHP penetration. With the purpose of analyzing this effect, two extra room temperatures are used for the creation of the corresponding residential energy profiles, these temperatures are: 19 and $17^{\circ} \mathrm{C}$

In this context, the complete Probabilistic Impact Assessment is executed for each of the new pools of energy profiles $\left(19\right.$ and $17^{\circ} \mathrm{C}$ ) and the percentage of customers with voltage problems and the utilization at the head of the feeder are again determined. With these two metrics, it is possible to determine the new penetration level when the problems start (first occurrence of problems) and then by comparing with Table II, the improvement of the action can be determined. Indeed, Table III shows the extra penetration that is possible to achieve by using the new set temperatures in comparison with the base case. For example, the reduction of $2^{\circ} \mathrm{C}$ in the set temperature just enables an additional $10 \%$ of EHP penetration in feeder 3 of network 3 (i.e., the first occurrence of problems was delayed from 30 to $40 \%$ ). Table III also indicates that decreasing the temperature (even $4^{\circ} \mathrm{C}$ ) does not 
TABLE III. GAINS IN EHP PENETRATION (\%) - RADIATOR

\begin{tabular}{c|c|c|c}
\cline { 2 - 4 } & Feeder & $19^{\circ} \mathrm{C}$ & $17^{\circ} \mathrm{C}$ \\
\hline \multirow{3}{*}{ Network 1 } & 1 & 0 & 10 \\
\cline { 2 - 4 } & 2 & 20 & 20 \\
\cline { 2 - 4 } & 3 & 10 & 20 \\
\cline { 2 - 4 } & 4 & 0 & 0 \\
\hline Network 2 & 3 & 10 & 20 \\
\hline \multirow{2}{*}{ Network 3 } & 1 & 10 & 10 \\
\cline { 2 - 4 } & 3 & 10 & 20 \\
\hline
\end{tabular}

delay the occurrence of problems in all the feeders with technical issues. Furthermore, the average magnitude of the additional improvement in these cases is only about 9 and $14 \%$ of penetration level, for the cases with 19 and $17^{\circ} \mathrm{C}$ set temperatures, respectively.

Another alternative to increase the penetration of EHPs at the residential level is the utilization of a more efficient heat emitter. For that reason, in this work, the utilization of underfloor heating is also investigated. This emitter uses a much larger heat exchange surface than the radiator and therefore the delivery temperature could be lower (40 instead of $55^{\circ} \mathrm{C}$ ), requiring less energy for the EHP. Therefore, in this case, the residential energy profiles creation is carried out by considering this type of heat emitter instead of the radiator and a set of three room temperatures: 21,19 and $17^{\circ} \mathrm{C}$, to allow the comparison with the previous case.

Once the corresponding pools of profiles are created, the Probabilistic Impact Assessment Methodology is executed for each of them. Hence, the gains of penetration levels with respect to the base case (radiator and $21^{\circ} \mathrm{C}$ ) for these new studies are presented in Table IV, showing that the adoption of underfloor heating enables at least additional $20 \%$ of extra penetration level for those feeders with problems. It is important to highlight that this extra gain is above $40 \%$ for several feeders. In fact, the average increase in penetration level is 38,38 and $42 \%$ for the cases with 21,19 and $17^{\circ} \mathrm{C}$. Comparison with the radiator case also reveals that the reduction in the set temperature does not delay significantly the occurrence of the first problems. In fact, for the underfloor heating cases, the reduction from 21 to $19^{\circ} \mathrm{C}$ does not improve the results and the reduction to $17^{\circ} \mathrm{C}$ produces only some improvement.

\section{B. Household Comfort}

The utilization of different heat emitters and different set temperatures could affect the comfort at the household level. To quantify that, the daily indoor average temperature (considering only the periods with people at home and awake) for each of the profiles created for each of the cases is presented in Fig. 4.

This box plot indicates the median temperature (red line inside the box), the $75^{\text {th }}$ and $25^{\text {th }}$ percentiles (edge of the boxes, so that $50 \%$ of the data is inside the box), the $95^{\text {th }}$ and $5^{\text {th }}$ percentiles (the upper and lower black lines) and outliers (the red crosses). Thus, Fig. 4 shows that the utilization of lower set temperatures can lead to average temperatures lower than $15^{\circ} \mathrm{C}$ for some houses in the implemented networks. In addition, it is possible to observe that the daily average temperature for the same target in the underfloor heating cases is lower than in the radiator cases. This is produced because of the larger thermal inertia and, therefore, a longer period is
TABLE IV. GAINS IN EHP PENETRATION - UNDERFLOOR HEATING

\begin{tabular}{c|c|c|c|c}
\cline { 2 - 5 } & Feeder & $21^{\circ} \mathrm{C}$ & $19^{\circ} \mathrm{C}$ & $17^{\circ} \mathrm{C}$ \\
\hline \multirow{3}{*}{ Network 1 } & 1 & 50 & 50 & 60 \\
\cline { 2 - 5 } & 2 & 50 & 50 & 50 \\
\cline { 2 - 5 } & 3 & 30 & 30 & 30 \\
\cline { 2 - 5 } & 4 & 20 & 20 & 30 \\
\hline Network 2 & 3 & 40 & 40 & 40 \\
\hline \multirow{2}{*}{ Network 3 } & 1 & 30 & 30 & 40 \\
\cline { 2 - 5 } & 3 & 50 & 50 & 50 \\
\hline
\end{tabular}

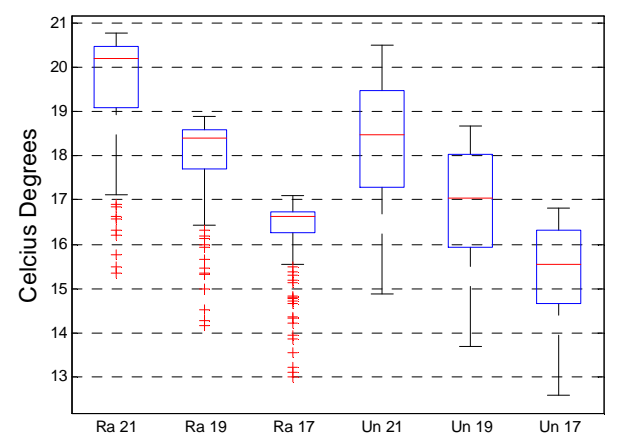

Figure 4. Daily average temperature per house using radiators (Ra) and underfloor heating (Un)

required to achieve the corresponding set temperature. This effect could be mitigated by the incorporation of a setback temperature (i.e., requirement of a minimum temperature that should be satisfied at any moment during the day). This action will be explored in the next section.

\section{SENSITIVITy CASE: SETBACK TEMPERATURES}

The incorporation of a setback temperature will improve the average daily temperature in each household, avoiding temperatures below a certain comfort zone. However, the effect of this action on the EHP impacts in LV distribution networks is not clear. For instance, in order to keep the room temperature above certain threshold, the EHP operation could be triggered more often than in the base case, and therefore could produce an additional impact on the LV infrastructure. On the other hand, a significant decrease in the room temperature (e.g., no setback) could also lead to problems in the $\mathrm{LV}$ feeder due to the longer period required to achieve the target temperature after that particular decrease.

With the purpose of truly understanding the effect of the setback temperature, this section analyzes all the previous cases with the incorporation of a setback of $15^{\circ} \mathrm{C}$. Thus, six new pools of profiles are created, namely, three radiator cases and three under floor heating cases with set temperatures of 21,19 and $17^{\circ} \mathrm{C}$ and a setback temperature of $15^{\circ} \mathrm{C}$. For each of these additional cases, the Probabilistic Impact Assessment is carried out, determining for each of them the corresponding voltage and congestion problems. With the results, and by comparing with the base case, it is possible to determine the gains in the penetration level of EHPs in the network under analysis. These results are presented in Table V and VI for the radiator and underfloor heating cases, respectively. These tables show lower gains in EHP penetration in comparison with the cases without setback temperature. For instance, the radiator cases with setback (Table $\mathrm{V}$ ) produce average increases, among the feeders with problems, of 0,6 and $10 \%$, for the set temperatures of 21,19 and $17^{\circ} \mathrm{C}$, respectively. 
TABLE V. GAINS IN EHP PENETRATION - RADIATOR AND SETBACK TEMPERATURE

\begin{tabular}{c|c|c|c|c}
\cline { 2 - 5 } & Feeder & $21^{\circ} \mathrm{C}$ & $19^{\circ} \mathrm{C}$ & $17^{\circ} \mathrm{C}$ \\
\hline \multirow{3}{*}{ Network 1 } & 1 & 0 & 0 & 10 \\
\cline { 2 - 5 } & 2 & 0 & 10 & 20 \\
\cline { 2 - 5 } & 3 & 0 & 10 & 10 \\
\cline { 2 - 5 } & 4 & 0 & 0 & 0 \\
\hline Network 2 & 3 & 0 & 0 & 10 \\
\hline \multirow{2}{*}{ Network 3 } & 1 & 0 & 10 & 10 \\
\cline { 2 - 5 } & 3 & 0 & 10 & 10 \\
\hline
\end{tabular}

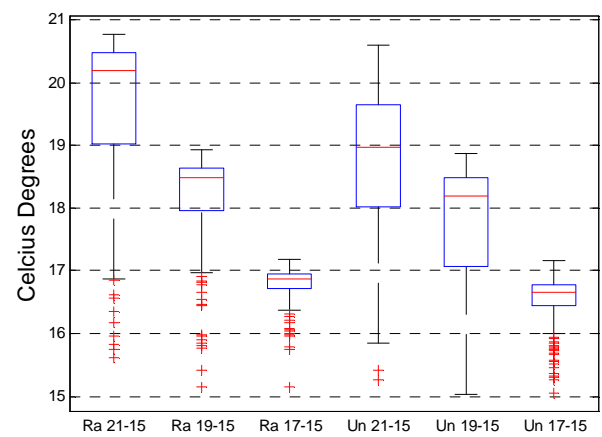

Figure 5. Daily average temperature per house using radiators (Ra) and underfloor heating (Un) - Setback cases

These percentages are also lower in the underfloor heating cases with setback (Table VI). In fact, the average increase among the feeders with problems is 31,31 and $35 \%$ for the set temperatures of 21,19 and $17^{\circ} \mathrm{C}$, respectively.

Although, the incorporation of a setback temperature does not help to further increase the penetration level of EHPs, it maintains the temperature at adequate levels (always above 15 ${ }^{\circ} \mathrm{C}$ ), increasing the daily average temperature observed (during active occupancy) in the households. This is particularly clear in the underfloor heating cases, where the average temperatures are about $1^{\circ} \mathrm{C}$ higher than in the case without setback.

\section{CONCLUSIONS}

In this work the impacts of adopting EHPs at residential levels and possible actions to minimize them were examined through the implementation of three real UK LV networks (17 feeders in total). The EHP impacts and mitigation actions were analyzed through a Probabilistic Impact Assessment methodology based on a Monte Carlo approach, using oneminute time series power flow and the incorporation of detailed UK domestic energy profiles (power consumption and heat requirements). These profiles considered the modelling of electrical appliance consumption, domestic hot water consumption, heating unit, heat distribution system, heat emitter and building models. Different penetration levels (percentage of houses with EHP) ranging from $0 \%$ to $100 \%$ were analyzed. A three-phase four wire representation was used to model all the studied feeders.

The base case explored consisted of loads and EHP profiles created assuming modern UK semi-detached houses for a cold day (daily average of $1.7^{\circ} \mathrm{C}$ ), the utilization of radiators as heat emitters and a set temperature of $21^{\circ} \mathrm{C}$.
TABLE VI. GAINS IN EHP PENETRATION - UNDERFLOOR HEATING AND SETBACK TEMPERATURE

\begin{tabular}{c|c|c|c|c}
\cline { 2 - 5 } & Feeder & $21^{\circ} \mathrm{C}$ & $19^{\circ} \mathrm{C}$ & $17^{\circ} \mathrm{C}$ \\
\hline \multirow{3}{*}{ Network 1 } & 1 & 30 & 30 & 40 \\
\cline { 2 - 5 } & 2 & 50 & 50 & 50 \\
\cline { 2 - 5 } & 3 & 30 & 30 & 30 \\
\cline { 2 - 5 } & 4 & 10 & 10 & 20 \\
\hline Network 2 & 3 & 40 & 40 & 40 \\
\hline \multirow{2}{*}{ Network 3 } & 1 & 20 & 20 & 20 \\
\cline { 2 - 5 } & 3 & 40 & 40 & 50 \\
\hline
\end{tabular}

The Probabilistic Impact Assessment was applied for this base case over the three real UK LV networks implemented, showing that $41 \%$ of the feeders under analysis present technical issues at some penetration level for the base case. Interestingly, most of them show only thermal issues (utilization level higher than $100 \%$ at the head of the feeder).

To minimize the impacts in the feeders with technical problems, two mitigation actions were analyzed: modification in the set temperature (indoor required temperature) and the utilization of underfloor heating as emitter unit. The assessment of these actions shows that decreasing the set temperature can only slightly increase the EHP penetration (e.g., $9 \%$ in average for a reduction of $2{ }^{\circ} \mathrm{C}$ ). In contrast, the consideration of underfloor heating can allow in average a $38 \%$ of extra penetration in the networks under analysis.

Finally, the incorporation of a setback temperature of 15 ${ }^{\circ} \mathrm{C}$ does not help to further increasing the penetration level of EHPs, but allows more comfortable indoor temperatures, particularly in the underfloor heating cases.

\section{REFERENCES}

IPCC, "Summary for Policymakers. In: Climate Change 2013: The Physical Science Basis. Contribution of Working Group I to the Fifth Assessment Report of the Intergovernmental Panel on Climate Change," 2013.

[2] Department of Energy and Climate Change, "Estimates of heat use in the United Kingdom in 2012," UK, 2013.

A. Navarro-Espinosa and P. Mancarella, "Probabilistic modeling and assessment of the impact of electric heat pumps on low voltage distribution networks," Appl. Energy, vol. 127, pp. 249-266, Aug. 2014.

[4] A. Navarro-Espinosa, L. F. Ochoa, and D. Randles, "Monte CarloBased Assessment of PV Impacts on Real UK Low Voltage Networks," in Proc. of IEEE Power \& Energy Society General Meeting, July 2013.

[5] N. Good, L. Zhang, A. Navarro-Espinosa, and P. Mancarella, "High resolution modelling of multi-energy domestic demand profiles," Appl. Energy, vol. 137, pp. 193-210, Jan. 2015.

[6] P. Mancarella, C. K. Gan, and G. Strbac, "Evaluation of the impact of electric heat pumps and distributed CHP on LV networks," in Proc. of IEEE PES Power Tech, June 2011.

[7] M. Akmal, B. Fox, D. J. Morrow, and T. Littler, "Impact of High Penetration of Heat Pumps on Low Voltage Distribution Networks," in Proc of IEEE PES PowerTech 2011, June 2011.

[8] R. C. Dugan and T. E. Mcdermott, “An Open Source Platform for Collaborating on Smart Grid Research," in Proc. of IEEE Power and Energy Society General Meeting, July 2011.

[9] I. Richardson, M. Thomson, D. Infield, and C. Clifford, "Domestic electricity use: A high-resolution energy demand model," Energy Build., vol. 42, no. 10, pp. 1878-1887, Oct. 2010.

[10] Brisitsh Standards Institution, "BS EN 50160: Voltage characteristics of electricity supplied by public distribution systems," 2000. 